\title{
Drug treatment
}

\author{
Michael Prendergast
}

This is the eleventh of a series of articles on treatment of child psychiatric disorders.
The Children's Hospital, Ladywood Middleway, Ladywood, Birmingham B16 8ET Correspondence to: Dr Prendergast.
There is general agreement that psychoactive drugs should only be given as part of an overall treatment plan. It might be thought there would also be general agreement that the use of psychoactive drugs should be informed by the literature but there are such large differences in prescribing practice between clinicians and between countries that other factors must be relevant. Stimulant drugs are probably the best investigated and best understood psychoactive drugs in use in childhood and yet they are seldom prescribed in Britain, where drugs are frequently used to treat sleep problems and nocturnal enuresis. ${ }^{12}$ Both of these conditions are more appropriately managed with behavioural methods. On the other hand, some severe psychiatric problems are unusual and little researched in childhood or adolescence. One can appeal to the adult literature but it may not be relevant. There are a number of recent reviews of pharmacotherapy which differ in emphasis and which are helpful in whole or in part. $^{3-7}$

There is still quite a gap between our knowledge of what drugs can do biochemically and why they make some problems better. Most psychoactive drugs affect more than one neurotransmitter system, ${ }^{8}$ so this account leaves neurotransmitters aside and matches operationally defined syndromes with drugs believed to alter target symptoms within these syndromes.

\section{Sleep problems}

Difficulty in settling, 'midnight intruder', and dawn rising are common sleep problems in the toddler years and respond well to behavioural methods, which are the treatment of choice. ${ }^{9}$ Prescription of hypnotics to children is contraindicated by the British National Formulary ${ }^{10}$; despite this, their use is widespread. ${ }^{1}$ Trimeprazine (Vallergan, RhônePoulenc Rorer) works well in the short term ${ }^{11}$ and may be used in a crisis, for example, when parents are severely sleep deprived themselves. Tolerance develops rapidly and if the response is to increase the dose the child may become zombie-like and drool throughout the day. Data sheets for Vallergan now contain an expanded section on the risk of tardive dyskinesia, which is another reason for caution. Chloral is an alternative for short term use. Benzodiazepines are best avoided in childhood because of their behavioural toxicity.

Occasional nightmares are common and can usually be related to a frightening experience. If frequent they should be inquired into. Night terrors, sleep walking, and sleep talking are parasomnias and often respond to explanation and reassurance. ${ }^{12}$ When they are frequent and occur at a predictable time of the night, they can sometimes be controlled by pre-emptive waking. ${ }^{13}$ Drug treatment is rarely necessary. Low dose benzodiazepines have been used and there are reports of successful use of both imipramine $^{14}$ and carbamazepine ${ }^{15}$ which may be preferred.

Narcolepsy and other hypersomnias are seldom diagnosed in childhood. Psychostimulants, for example, methylphenidate or dexamphetamine, and more recently mazindol, ${ }^{16}$ are favoured in the adult literature. Clomipramine may reduce the frequency of narcoleptic attacks and of cataplexy which is loss of tone without loss of consciousness. ${ }^{12}$ Dietary tyrosine supplements have been found helpful in reducing hypersomnia in adults in some hands ${ }^{17}$ but not in others. ${ }^{18}$ Quantitative serum tyrosine monitoring is prudent in childhood.

\section{Confusion and delirium}

Confusion and delirium are medical emergencies and this is the first line of management. Fever or other signs may point to a medical cause and non-convulsive status epilepticus is one of many conditions that must be considered. Drugs may be responsible, whether medically prescribed or illicitly obtained, through idiosyncratic reaction or overdose.

When a drug is responsible for the reaction, it should be stopped where possible. Disorientation and behaviour disturbance are often more prominent at night and chloral is effective if only night sedation is required.

Where behaviour disturbance is jeopardising treatment, the short term use of chlorpromazine is recommended, in doses sufficient to confine the child to bed, combined with adequate illumination and sensitive nursing care. Such reactions are usually shortlived.

Children with dementing illnesses associated with behavioural problems may rarely require chronic sedation, for example, chlorpromazine or thioridazine which should be prescribed in the lowest dose effective and in higher dose at night if night time sedation is also required. The oral route is preferred as intramuscular injections may be interpreted as attacks. Where tablets are not tolerated and when thiordazine is chosen, the suspension should be used as the liquid is extremely unpalatable.

\section{Schizophrenia, hallucinations, and neuroleptic drugs}

Schizophrenia of adult type is rare in prepuber- 
tal children, although it becomes more common in adolescence. Its management is a specialist matter and will often involve inpatient treatment in a dedicated unit. An underlying physical disorder should always be sought. Treatment is symptomatic and based upon the symptoms present at the time.

As drug treatment hinges upon neuroleptics with their attendant long term risk of tardive dyskinesia, non-drug alternatives can and perhaps should be tried where appropriate, although it is recognised that most units do not do this.

Auditory hallucinations may respond to an ear plug. ${ }^{19}$ It should be placed in the more impaired ear where there is a difference, and when the patient will tolerate it. Visual hallucinations are usually paroxysmal and distorting spectacles interfere with them if the patient can be persuaded to sit down and use them. Both these types of hallucinations can occur in plain consciousness in the absence of psychosis. ${ }^{20} 21$ In these circumstances, compliance with the treatments suggested above may be easier to obtain.

The drug treatment of children and adolescents with schizophrenia is little researched and practice is based upon analogy with the adult literature.

It is important to appreciate the huge differences in potency between neuroleptics. A dose of $100 \mathrm{mg}$ of chlorpromazine is equivalent to $100 \mathrm{mg}$ of thioridazine, but $5 \mathrm{mg}$ of trifluoperazine and only $2 \mathrm{mg}$ of haloperidol and only $2 \mathrm{mg}$ of pimozide, but $200 \mathrm{mg}$ of sulpiride and $40 \mathrm{mg}$ of clozapine. In general, the more potent neuroleptics carry a greater risk of extrapyramidal side effects and the less potent neuroleptics are more sedative, but still have extrapyramidal side effects. Dependent upon the degree of disturbance at presentation, sedation may be the first priority. Otherwise, a period of drug free inpatient observation by experienced staff is preferable and may be all that is required in some brief psychotic episodes.

Subsequent management in those requiring medication will comprise a systematic trial of several weeks of a drug from each of the various groups given individually according to tolerance. Typical representatives would be chlorpromazine, thioridazine, sulpiride, and haloperidol. Depot neuroleptics are usually avoided until a stable response has been obtained, if they are to be used at all.

Unfortunately, a therapeutic margin between symptom relief and side effects can be hard to find in the prepubertal patient. ${ }^{22}$ Clozapine offers hope for treatment resistant patients but it is only licensed for use in children older than 12 years subject to compliance with an expensive monitoring procedure to guard against agranulocytosis. ${ }^{23}$

Drug treatment mainly affects the positive symptoms of hallucinations and delusions. It has very little effect on the negative motivationless state that some patients are left with. Ciompi has drawn attention to the various patterns of schizophrenic illness. ${ }^{24}$ Only some forms imply 'medication of life'. Once control is achieved, a decision must be made whether to try the patient on a diminished drug dosage while still in hospital, or after safe return home. The issue of continued treatment should be kept under continual review. Antiparkinsonian agents are not prescribed routinely but are only given if the relevant side effects occur.

Patient and parents must be warned of the possibility of writhing, dystonic movements of the face and body, and oculogyric crisis in the first few days of treatment with neuroleptics and of parkinsonian symptoms of tremor, rigidity, akinesia, and salivation in the succeeding weeks. All of these symptoms respond to antiparkinsonian agents or medication reduction. Acute dystonic reactions are distressing and they are medical emergencies. Parents of children who are managed as outpatients may be given a few procyclidine tablets or equivalent to use, if required, pending attendance at a casualty department. Intramuscular injection of an antiparkinsonian drug will bring more immediate relief.

Some patients experience akathisia, an unpleasant restless agitation, usually within the first two months of starting a neuroleptic. It can be difficult to treat without drug reduction. Adult work indicates akathisia is relatively resistant to antiparkinsonian drugs but propranolol may be helpful. Clonazepam has been shown to be effective in some adolescent cases. $^{25}$

More seriously, neuroleptic malignant syndrome may present at any time. ${ }^{26}$ In its florid state it is characterised by fever, fluctuating consciousness, autonomic instability, increased tone, and raised serum creatinine kinase. Formes frustes occur and fever or raised enzymes may be lacking. It is a potentially lethal condition. Neuroleptics must be stopped at once. Symptoms may take a week or more to respond but longer if the patient has taken a depot neuroleptic.

Dantrolene and bromocriptine have been used but the essence of treatment is attention to fluid balance and cardiorespiratory support in a medical setting.

Tardive dyskinesia is an important long term risk of neuroleptic treatment. It may be transient and appear as a withdrawal dyskinesia lasting from days to several months, or it may be persistent. In tardive dyskinesia irregular choreoathetoid movements occur predominantly in the buccal-lingual musculature and at the distal extremities. It is not uncommon in children exposed to neuroleptic, $25 \%$ in one series. ${ }^{27}$ Mentally retarded patients are at greater risk and also at greater risk of neuroleptic treatment. Tardive dystonia is a more malignant variant characterised by sustained contraction of skeletal musculature, manifest as, for example, sustained tongue protrusion, disabling posturing, stridor from laryngospasm, and dysarthria. ${ }^{7} 28$ In addition, Gualtieri has described a late onset behavioural equivalent of tardive dyskinesia that he terms tardive akathisia with dysphoria and motor restlessness. ${ }^{7}$

All these conditions are difficult to treat beyond withdrawal of neuroleptics and waiting. They may be irreversible but remission rates in children are fortunately higher than in adults. 
Non-extrapyramidal side effects of neuroleptics include gynaecomastia, galactorrhoea, amenorrhoea, weight gain, and jaundice. Chlorpromazine is particularly associated with photosensitive reactions and thioridazine with a pigmentary retinopathy in high dose.

\section{Hypomania and bipolar illness}

Hypomania is characterised by elevated mood, excitement and irritability, pressure of talk and flight of ideas, which are often grandiose. Teenagers are disinhibited and sleep little. Mania is a more florid version of the same. It is rare, even reportable before the teenage years. ${ }^{29}$ In the acute phase, sedation with a major tranquilliser and hospital admission may be required. Hypomanic episodes may be recurrent, or more usually part of a bipolar illness. Children and teenagers with bipolar disorders have recurrent episodes of severe depression and hypomania. Lithium carbonate is the treatment of choice. ${ }^{60}$ Because of differences in bioavailability, it is important to choose a preparation and stay with it.

Sustained release lithium carbonate can be given twice daily and blood concentrations are monitored in the steady state, 12 hours after the previous dose. In practice this means about five days after the last dose increase. Target serum concentrations are usually within the range of $0.6-1.0 \mathrm{mmol} / \mathrm{l}$. When control is obtained, measurements are repeated every six weeks or so and also thyroid function tests and tests of renal function are performed-less frequently but more often if there is cause for concern. Fluid loss through vomiting, diarrhoea, and sweating in hot weather can all cause toxicity that is characterised by diarrhoea, vomiting, tremor, ataxia, dysarthria, and muscular weakness progressing to cardiac arrhythmia, stupor, and death if lithium is continued. Less severe side effects include polydipsia, polyuria, weight gain, and thyroid dysfunction. Previous worries about nephrotoxicity seem to have been exaggerated. $^{31}$

In rapid cycling bipolar illnesses there are three or more occurrences within a year. Sometimes there may be several mood swings within a week. Carbamazepine can be used as an alternative to lithium carbonate in unresponsive patients and as a treatment of choice in rapid cycling patients. ${ }^{32}$ Dosages are the same as in the treatment of epilepsy and the sustained release preparation is preferred.

\section{Depression}

Depression of adult type is increasingly recognised in childhood. In the past it was probably included in the category of emotional disorders without further inquiry.

When suspected, the child must be interviewed alone and suicidal ideas inquired after. A decision should be made whether referral for inpatient treatment is required. Although child psychiatrists use antidepressants to treat more serious depressions ${ }^{2}$ evidence to support this practice is so far lacking from double blind trials and the issue is unresolved. There is little experience with the new antidepressants.
Typically, amitriptyline is used for its sedative effect in the agitated patient and imipramine is used for its more stimulant effect in the patient who has slowed up. Patients and parents should be warned about the early appearance and resolution of the anticholinergic effects of dry mouth, constipation, and blurred vision. These are not usually problematic if the drug is introduced slowly. Children seem to require $75-100 \mathrm{mg}$ daily on average and starting at 25 mg at night, the dose can be increased by a similar increment every three days or so.

The antidepressant effect is not usually obtained before about 10 days of treatment at the appropriate dose. In treatment responders antidepressants are usually continued for about three months after response is obtained. I do not usually begin withdrawal of drugs at critical times, for example, at the start of the new school year. Intersubject absorption of imipramine varies considerably and monitoring of blood concentrations is recommended when this tricyclic is used. Puig-Antich et al have suggested that a total plasma concentration of $150 \mu \mathrm{g} / \mathrm{l}$ (imipramine and desipramine) is necessary for therapeutic effect. ${ }^{33}$ Serial electrocardiographic (ECG) records are recommended if high doses of imipramine are needed to achieve this. ${ }^{6}$ Clearly, parents must understand the need to supervise the taking of tablets and to keep them away from the patient and younger siblings. Childproof containers are essential. ${ }^{34}$

Sleep deprivation or deprivation of rapid eye movement sleep as treatments for depression have yielded inconsistent results but may offer a treatment alternative for antidepressant resistant patients. ${ }^{3536}$

Very severe depressive illness unresponsive to antidepressants, depressive stupor, and catatonic stupor are rare indications for electroconvulsive treatment. It should not be undertaken without further supportive consultant opinions, perhaps from colleagues in adolescent psychiatry and adult psychiatry, in addition to the usual thorough discussion with patient and parents. The great advantage of electroconvulsive treatment is rapid relief when it is successful. ${ }^{37}$

\section{Obsessive compulsive disorders and trichotillomania}

The manifestations of obsessive compulsive disorder include repetitious checking and other rituals and compulsions which often involve the whole family. Children who are severely handicapped by these symptoms may require inpatient treatment.

Behavioural management has a role but it is less powerful in this condition than was originally thought. Clomipramine is effective, even in the absence of coexisting depressive symptomatology. ${ }^{38} 39$ Trichotillomania responds to the same drug, ${ }^{40}$ but this should not be taken as evidence that the nature of these two conditions is similar.

\section{Tics and Tourette's syndrome}

Simple motor tics are widespread, transient, and can usually be managed with explanation 
and reassurance. The syndrome of Gilles de la Tourette comprises multiple motor tics and phonic tics. Medication is only indicated when the tics are intrusive and handicapping. There is no evidence that early treatment modifies the course of the disease.

Haloperidol is best researched and often cited as the treatment of choice. ${ }^{41}$ Acute extrapyramidal reactions are common and patients should be warned of the possibility of tremor, stiffness, and oculogyric crisis, all of which will respond to antiparkinsonian agents, for example procyclidine. Antiparkinsonian drugs should only be taken if these problems arise. Haloperidol can cause excessive sedation which has been termed a 'fog' state. ${ }^{42}$ Sulpiride ${ }^{28}$ and pimozide ${ }^{43}$ can also cause extrapyramidal reactions but are less likely to and appear to have broadly similar efficacy. ${ }^{44}$

Because of reports of sudden death due to arrhythmias, pimozide is less used now. Prior ECG and subsequent monitoring is advisable and a response will have usually been achieved by $8 \mathrm{mg}$ in a single daily dose if it is to occur. ${ }^{43}$

Phonic tics are usually the first to respond to drug treatment and then complex motor tics and then simple motor tics.

Tourette's syndrome may be associated with other psychopathology, particularly obsessive compulsive symptoms. Rhythmic complex movements that appear compulsive, for example, repetitive kissing or lining up are called complex tics in the American literature, but as they seem to lie between Tourette's syndrome and obsessive compulsive disorder, they are perhaps best referred to as complex movements. Sometimes these movements are the main problem. Neuroleptics usually leave them untouched but they will often respond to clomipramine where specific treatment is required.

Tics wax and wane but some children go into 'status tic', a sequence of unrelenting tics and complex movements that leaves them sore and exhausted. In the absence of a more specific remedy, chloral induced sleep will sometimes bring relief.

Clonidine has its advocates and has the advantage that it is not a neuroleptic but there are doubts about its efficacy ${ }^{45}$ and in my hands it causes depression and does not affect the tics at all.

Naturally there are concerns about the lifetime risk of tardive dyskinesia in this new cohort of children receiving long term neuroleptics. Drug free days are advised once or twice a week, perhaps at weekends, to diminish the lifetime weight of drug consumed. Treatment alternatives under investigation include buspirone and calcium channel blockers.

Anxiety, panic attacks, and school refusal Situational anxieties or phobias are best treated with behavioural methods. In school refusal in the younger child, anxieties are multifactorial and early return to school is the cornerstone of management. Anxiolytics have been used but results are conflicting as to their efficacy. Benzodiazepines are best avoided because of their addictive potential and propensity to behavioural side effects.
Free floating anxiety and panic attacks may be associated with hyperventilation which can be assessed in the clinic. Propranolol may be helpful but is contraindicated when there is a history of asthma or arrhythmia. It has the advantage that it can be taken 'as required'. The tricyclic drugs, amitriptyline and imipramine can be given for their anxiolytic effects. The present generation of monoamine oxidise inhibitors (MAOIs) is difficult to use because of the food restrictions required to avoid a pressor reaction. The newer reversible inhibitors of monoamine oxidase, for example, moclobemide may render this category of drugs more available to teenage patients.

\section{Hysterical disorders and eating disorders}

Hysterical and somatising disorders are included here because they are sometimes complicated by depression which should be diagnosed and treated in the usual way. Likewise, the depression sometimes found in chronic fatigue syndromes and anorexia nervosa. Abreaction with intravenous amylobarbitone ${ }^{46}$ can be helpful in the management of psychogenic stupor, as it is difficult to gain therapeutic access to a patient who can neither move nor talk. ${ }^{47}$

There is no specific drug treatment for anorexia nervosa, but both imipramine and fluoxetine have found support in the treatment of bulimia nervosa. ${ }^{48}$

\section{Elimination}

The management of encopresis is not usually undertaken before age 4 years for developmental reasons. Constipation is frequently associated and laxatives may be required. The choice of laxative is important, but 'sister's favourite' is often prescribed by default. The area has been reviewed recently by Graham Clayden and is not further discussed. ${ }^{49}$

Likewise, developmental considerations determine nocturnal enuresis is not usually treated actively before age 5 years. There is abundant evidence that behavioural methods are the treatment of choice after physical causes have been rejected. Some children respond to simple star charts rewarding dry nights.

Other children require a night trainer alarm that uses the same principle as the bell and pad and is equally effective but more convenient. ${ }^{50}$ Many districts now have enuresis clinics to provide this service. Despite the above, amitriptyline and imipramine are still widely prescribed for nocturnal enuresis by general practitioners ${ }^{1}$ and child psychiatrists. ${ }^{2}$ Although effective in the short term, relapse is frequent when the drug is stopped and the risk of overdose by patient or siblings is well known. ${ }^{34}$

There may be a place for prescribing one of these drugs in the short term, for example, to allow a child to go on a school holiday and the same can also be said for intranasal desmopressin, ${ }^{51}$ but in the presence of safer, more effective behavioural methods the widespread use of drugs to treat nocturnal enuresis cannot be endorsed.

In daytime wetting, behavioural methods 
including regular potting are the mainstay of treatment, but urodynamic review should be considered, particularly when there is associated urgency. Most of the drugs used by urodynamicists can provoke nightmares.

\section{Hyperactivity}

Children with pervasive short attention span and restless, overactive, distractable behaviour meet criteria for hyperkinetic disorder according to the International Classification of Diseases, 9th revision ${ }^{52}$ and attention deficit disorder in the American system Diagnostic and Statistical Manual of Mental Disorders, 3rd revision revised. ${ }^{53}$ Attention deficit disorder defines a much broader group as it also includes situational expression of these problems and it is not further discussed here.

Hyperkinetic disorder, narrowly defined, is of early onset and occurred at a rate of 17 per 1000 boys aged $6-8$ years in the east London study ${ }^{54}$ British child psychiatrists are reluctant to make this diagnosis but usually identify the conduct disorder with which it is often associated. ${ }^{55}$ Hyperkinetic syndrome is a handicapping condition. Management is difficult and requires attention to structure and consistency which usually involves environmental manipulation. Stimulant drugs are widely used in America; probably the best researched psychotropic drugs in use in childhood and scarcely used in Britain. Even if reserved for the most severely afflicted children who show this behaviour at home, at school, and in the doctor's office, every health district has candidate patients.

After diagnosis, baseline parent and teacher ratings using the Rutter ${ }^{56}$ or Conners scales $^{57}$ are completed which takes a few minutes. These can be repeated serially to assess change. Methylphenidate ${ }^{58}$ and dexamphetamine are both effective. A Yes-No effect is sought. When there is benefit it is clear and the school dinner lady will notice if a tablet is omitted. What is more, the child's improved behaviour is likely to have a positive effect on family interaction. ${ }^{59}$

Methylphenidate is only available in the UK on a named patient basis from the company (CIBA Laboratories, Horsham, West Sussex RH12 4AB). It has a short half life and it is given in divided doses in the range of $0.3-1.5$ $\mathrm{mg} / \mathrm{kg} /$ day starting with about $5 \mathrm{mg}$ daily depending on the size of the child. ${ }^{5}$ Appetite suppression is sometimes a problem so I usually give it after breakfast, after lunch, and maybe after school. Evening doses cause insomnia.

Reversible growth failure is reported and is probably related to high dose regimens. Nevertheless, height, weight, and blood pressure should be measured at each clinic attendance and this means the clinic should be equipped to do this. Drug 'holidays' are recommended for one or two days at weekends if this can be tolerated and for longer periods at least once a year. Some children become tearful or depressed and others may develop obsessive compulsive behaviour or tics. Tics are usually cited as a contraindication. ${ }^{6}$

Dexamphetamine is longer acting and may be given twice daily. The dose range is similar and so are the side effects. Some children tolerate one of these drugs more readily than the other. It is said that stimulants are ineffective in hyperactive children who are mentally handicapped, but a trial is still worthwhile in selected cases. ${ }^{60}$ Although both dexamphetamine and methylphenidate are controlled drugs, dependence is not a problem with the doses described here. Low dose imipramine, $25-15 \mathrm{mg}$ daily is a useful but less potent alternative. ${ }^{61}$

\section{Behaviour problems in children with epilepsy}

Children with epilepsy are at much greater risk of behaviour problems. The reasons for this are multiple but only drug issues are considered here.

It is profitable to review the anticonvulsants the child is taking. The behavioural side effects of carbamazepine are often associated with peak serum concentrations and a switch to the sustained release preparation at the same total daily dose is easy to do, will seldom result in decreased seizure control ${ }^{62}$ or deteriorating behaviour, but sometimes produces a gratifying behavioural improvement.

The behavioural side effects of phenobarbitone are well known and paediatricians hardly use it, but some adult specialists who also treat children are unfamiliar with this side effect.

Clonazepam and clobazam can both cause profound and chronic behavioural deterioration, even pseudodementia, if parents do not decide to stop giving them. There is sometimes cross reactivity between the two compounds but sometimes not, so it is worthwhile to try a switch. Hyperactive children with learning difficulties and intractable seizures, who have been on a benzodiazepine from an early age, are particularly at risk that the drug induced behaviour will be assumed to be constitutional. ${ }^{63}$

Vigabatrin has made a notable contribution to childhood psychopathology and can produce a spectrum of problems including psychosis.

One is reluctant to treat anticonvulsant induced hyperactivity with stimulants. Dexamphetamine raises the seizure threshold and is recommended over methylphenidate, which is said to lower it, in the treatment of constitutionally hyperactive children with epilepsy. In practice methylphenidate may ameliorate or alter the seizure pattern in addition to its expected effect.

\section{Behaviour problems in children who are} mentally handicapped ${ }^{7}$

Mentally handicapped children who present with behaviour problems divide conveniently into two groups those who are on drugs and those who are not. Those who are on drugs are probably on too many and sometimes show the fluctuating symptoms of a subacute confusional state. Treatment comprises drug rationalisation and reduction in the shadow of tardive dyskinesia.

Children and teenagers who present with behaviour problems severe enough to warrant consideration of drug treatment will usually have 
self injurious behaviour or challenging behaviour if they do not have a more conventional diagnosis, for example, depression or bipolar disorder, ${ }^{64}$ which should be treated appropriately. Sometimes there will be a more straightforward explanation, for example, toothache or departure of a familiar member of staff from a children's home.

Self injurious behaviour, for example, headbanging or eye gouging is very difficult to treat. ${ }^{65}$ Naltrexone has been tried in recent years with some success. ${ }^{4}{ }^{66}$ Carbamazepine can also be used. ${ }^{67}$ Challenging behaviour usually refers to explosive and aggressive behaviour in teenagers with limited language and limited responsiveness to social cues.

Management is expensive, person intensive and requires structure, continuity, and environmental manipulation. Regular exercise may also be of help. ${ }^{68}$ Drugs may have a role but should always be assessed with a serial record of the frequency of the target behaviours against a baseline taken before the drug was started.

Neuroleptics should be avoided as far as possible because of the risk of tardive dyskinesia that can follow even a short period of neuroleptic treatment at low dose. Their short term efficacy is seductive. Dependent upon assessment of the problem, a separate exhibition of carbamazepine, ${ }^{76970}$ propranolol, ${ }^{71}$ or lithium $^{672}$ may all be considered.

This world of chronic handicap is swept by enthusiasms. Fenfluramine has fallen out of favour for autism, ${ }^{43}$ but amantadine and calcium channel blockers are on the horizon. ${ }^{74}$

It is always a serious decision to recommend parents give drugs to their children. Sometimes it is a serious omission not to recommend parents give drugs to their children.

I am grateful to Mary Eminson for advice and support and to Claire Brittain for typing the manuscript.

1 Adams S. Prescribing of psychotropic drugs to children and adolescents. BM7 1991;302:217.

2 Bramble DJ. The use of anti-depressants by British child psychiatrists. Psychiatric Bulletin 1992;16:396-8.

Graham P. Child psychiatry: a developmental approach. 2nd Ed. Oxford: Oxford University Press, 1991.

4 Gadow KD. Paediatric psychopharmacotherapy. A review of recent research. I Child Psychol Psychiatry 1992;33: recent $153-95$.

5 Hyman SE, Arana GW. Handbook of psychiatric drug therapy. 2nd Ed. Boston: Little Brown, 1991.

6 Green WH. Child and adolescent clinical psychopharmacology. Baltimore: Williams and Wilkins, 1991.

7 Gualtieri CT. Neuropsychiatry and behavioural pharmacology. New York: Springer-Verlag, 1991

8 Cooper JR, Bloom FE, Roth RH. The biochemical basis of neuropharmacology. New York: Oxford University Press, 1991

9 Douglas J, Richman N. My child won't sleep. Harmondsworth: Penguin, 1984.

10 British Medical Assocation and the Royal Pharmaceutical Society of Great Britain. British national formulary. Number 23. London: BMA and the Royal Pharmaceutical Society of Great Britain, 1992:133.

11 Simonoff EA, Stores G. Controlled trial of trimeprazine tartrate for night waking. Arch Dis Child 1987;62:253-7.

12 Parkes JD. Sleep and its disorders. London: W B Saunders,

13 Lask $B$. Novel and non-toxic treatment for night terrors.

14 Pesikoff RB, Davis PC. Treatment of pavor nocturnus and somnambulism in children. Am $\mathcal{7}$ Psychiatry 1971;128: $778-81$.

15 Puente RM. The use of carbamazepine in the treatment of behavioural disorders in children. In: Birkmayer $W$, ed Epileptic seizures, behaviour, pain. Bern: Hans Huber Publishers 1976:243-52.

16 Alvare\% B, Dahlit\% M, Grimshaw J, Parkes JD. Mazindol in the long term treatment of narcolepsy. Lancet 1991;337: $1293-4$
17 Mouret J Sanchez P, Taillard J, Lemoine P, Robelin N, Canini $F$. Treatment of narcolepsy with $L$-tyrosine. Lancet 1988;ii:1458-9.

18 Elwes RDC, Chesterman LP, Jenner P, et al. Treatment of narcolepsy with L-tyrosine: double blind placebo controlled trial. Lancet 1989;ii: 1067-9.

19 Nelson HE, Trasher S, Barnes TRE. Practical ways of alleviating auditory hallucinations. BMF 1991;302:327.

20 Garralda ME. Hallucinations in children with conduct and emotional disorders: 1. the clinical phenomena. Psychol Med 1984;14:589-96.

21 Garralda ME. Hallucinations in children with conduct and emotional disorders: 2 . the follow-up study. Psychol Med 1984;14:597-604

22 Eggers C, Ropke B. Pharmacotherapy of schizophrenia in childhood and adolescence. In: Eggers C, ed. Schizophrenia and youth. Etiology and therapeutic consequences. Berlin: Springer-Verlag, 1991:182-95.

23 Siefen $G$, Remschmidt $H$. Results of treatment with clozapine in schizophrenic adolescents. Z Kinder Fugendpsychiatr 1986;14:245-57.

24 Ciompi L. Affect logic and schizophrenia. In: Eggers C, ed. Schizophrenia and youth. Etiology and therapeutic consequences. Berlin: Springer-Verlag, 1991:20.

25 Kutcher SP, MacKenzie S, Galarraga W, Szalai J. Clonazepam treatment of adolescents with neuroleptic induced akathisia. Am F Psychiatry 1987;144:823-4.

26 Turk J, Lask B. Neuroleptic malignant syndrome. Arch Dis Child 1991;66:91-2.

27 Perry R, Campbell M, Green WH, et al. Neuroleptic related dyskinesias in autistic children: a prospective study. Psychopharmacol Bull 1985;21:140-3.

28 Lees AJ. Tics and related disorders. Edinburgh: Churchill Livingstone, 1985.

29 Carlson GA. Child and adolescent mania-diagnostic considerations. F Child Psychol Psychiatry 1990;31:331-41.

30 Varanka TM, Weller RA, Weller EB, Fristad MA. Lithium treatment of manic episodes with psychotic features in prepubertal children. Am f Psychiatry 1988;145:1557-9.

31 Srinivasan DP, Abaya V, Birch NJ. Lithium therapy update. Hospital Update 1992;18:300-4.

32 Crawford $\mathrm{R}$, Silverstone T. Carbamazepine in affective disorder. International fournal of Clinical Psychopharmacology 1987;2(suppl 1)

33 Puig-Antich J, Perel JM, Lupatkin W, et al. Imipramine in pre-pubertal major depressive disorders. Arch Gen Psychiatry 1987;44:81-9.

34 Giles $\mathrm{H}$ McC. Imipramine poisoning in childhood. BM7 1963;ii:844-6.

35 Leibenluft B, Wehr TA. Is sleep deprivation useful in the treatment of depression? Am F Psychiatry 1992;149:159-68.

36 King BH, Baxter LR, Stuber M, Fish B. Therapeutic sleep deprivation for depression in children. $\mathcal{f}$ Am Acad Child Adolesc Psychiatry 1987;26:928-31.

37 Bertagnoli MW, Borchardt CM. A review of ECT for children and adolescents. 7 Am Acad Child Adolesc Psychiatry 1990;29:302-7.

38 Flament MF, Rapoport JL, Berg CJ, et al. Clomipramine treatment of childhood obsessive compulsive disorder. Arch Gen Psychiatry 1985;42:977-83.

39 DeVeaugh-Geiss J, Moroz G, Biederman J, et al. Clomipramine hydrochloride in childhood and adolescent obsessive compulsive disorder-a multicentre trial. 7 Am Acad Child Adolesc Psychiatry 1992;31:45-9.

40 Swedo SE, Rapoport JL. Trichotillomania. 7 Child Psychol Psychiatry 1991;32:401-9.

41 Shapiro AK, Shapiro E. Treatment of tic disorders with haloperidol. In: Cohen DJ, Bruun RD, Leckmann JF, eds. Tourette's syndrome and tic disorders: clinical understanding Tourette's syndrome and tic disorders: climical under

42 Bruun RD Subtle and underrecognised side effects of neuroleptic treatment in children with Tourette's disorder. $A m \mathcal{F}$ Psychiatry 1988;145:621-4.

43 Moldofsky $\mathrm{H}$, Sandor P. Pimozide in the treatment of Tourette's syndrome. In: Cohen DJ, Bruun RD, Leckman $\mathrm{JF}$, eds. Tourette's syndrome and tic disorders: clinical understanding and treatment. New York: J Wiley, 1988:282-9.

44 Shapiro E, Shapiro AK, Fulop G, et al. Controlled study of haloperidol, pimozide and placebo for the treatment of Gilles de la Tourette syndrome. Arch Gen Psychiatry 1989; 46: $722-30$

45 Leckman JF, Walkup JT, Cohen DJ. Clonidine treatment of Tourette's syndrome. In: Cohen DJ, Bruun RD, Leckman JF, eds. Tourette's syndrome and tic disorders: clinical under-

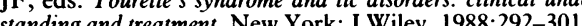

46 Perry C, Jacobs D. Overview: clinical applications of the amytal interview in psychiatric emergency settings. Am $\mathcal{7}$ Psychiatry 1982;139:552-9.

47 White A, Corbin DOC, Coope B. The use of thiopentone in the treatment of non-organic locomotor disorders. F Psychosom Res 1988;32:249-53.

48 Goldbloom DS, Kennedy SH, Kaplan AS, Woodside DB. Anorexia nervosa and bulimia nervosa. Can Med Assoc $\mathcal{Y}$ 1989;140:1149-54.

49 Clayden GS. Management of chronic constipation. Arch Dis Child 1992;67:340-4.

50 Fordham KE, Meadow SR. Controlled study of standard pad and bell alarm against mini alarm for nocturnal enuresis. Arch Dis Child 1989;64:651-6.

51 Evans JHC, Meadow SR. Desmopressin for bed wetting: length of treatment, vasopressin secretion, and response. Arch Dis Child 1992;67:184-8.

52 World Health Organisation. Mental disorders: glossary and guide to the classification in accordance with the ninth revision. 
of the international classification of diseases. Geneva: WHO, 1978 .

53 American Psychiatric Association. Diagnostic and statistical manual of mental disorders (DSM-III-R). 3rd Ed, revised. (a) 1987.

54 Taylor E, Sandberg S, Thorley G, Giles S. The epidemiology of childhood hyperactivity. Institute of Psychiatry Maudsley Monographs. London: Oxford University Press, 1991.

55 Prendergast M, Taylor E, Rapoport JL, et al. The diagnosis of childhood hyperactivity: a US-UK cross national study of DSM-III and ICD-9. F Child Psychol Psychiatry 1988;29: 289-300.

56 Rutter M, Tizard J, Whitmore K, eds. Education, health and behaviour. London: Longmans Green, 1970

57 Goyette $\mathrm{CH}$, Conners CK, Ulrich RF. Normative data on revised parent and teacher rating scales. $\mathcal{F}$ Abnorm Child Psychol 1978;6:221-36.

58 Taylor E, Schachar R, Thorley G, Wieselberg HM, Everitt B Rutter M. Which boys respond to stimulant medication? A controlled trial of methylphenidate in boys with disruptive controlled trial of methylphenidate in boys

59 Schachar R, Taylor E, Wieselberg M, Thorley G, Rutter M. Changes in family function and relationships in childre who respond to methylphenidate. $7 \mathrm{Am}$ Acad Child Adolesc Psychiatry 1987;26:728-32.

60 Gadow KD, Poling E. Pharmacotherapy and mental retardation. Boston: College Hill Press, 1988.

61 Rapoport JL, Quinn PO, Bradbard G, Riddle D, Brookes E. Imipramine and methylphenidate treatments of hyperactive boys: a double blind comparison. Arch Gen Psychiatry 1974; 30:789-93.

62 Ryan SW, Forsythe I, Hartley R, Haworth M, Bowmer CJ Slow release carbamazepine in treatment of poorly controlled seizures. Arch Dis Child 1990;65:930-5.

63 Commander M, Green SH, Prendergast M. Behavioural disturbances in children treated with clonazepam. Dev Med Child Neurol 1991;33:362-3.

64 McCracken JT, Diamond RP. Bipolar disorder in mentally retarded adolescents. 7 Am Acad Child Adolesc Psychiatry 1988;27:494-9.

65 Farber JM. Psychopharmacology of self iniurious behaviour in the mentally retarded. 7 Am Acad Child Adolesc Psychiatry 1987;26:296-302.

66 Barrett RP, Feinstein C, Hole WT. Effects of naloxone and naltrexone on self injury: a double blind placebo controlled analysis. Am f Ment Retard 1989;93:644-51.

67 Barrett RP, Payton JB, Burkhart JE. Treatment of self injury and disruptive behaviour with carbamazepine (Tegretol) and behaviour therapy. Fournal of the Multi-handicapped Person 1988;1:79-91.

68 McGimsey JF, Favell JE. The effects of increased physical exercise on disruptive behaviour in retarded persons. f Autism Dev Disord 1988;18:167-79.

69 Evans RW, Clay TH, Gualtieri CT. Carbamazepine in pediatric psychiatry. 7 Am Acad Child Adolesc Psychiatry 1987;26:2-8

70 Sovner $R$. Use of anticonvulsant agents for the treatment of neuropsychiatric disorders in the developmentally disabled. In: Ratey JJ, disabled. In. Rat JJ, ed. Mental retardation. developing Pharmacotherapies.

71 Ratey JJ, Lindem KJ. Beta blockers as primary treatment for aggression and self injury in the developmentally disabled. In: Ratey JJ, ed. Mental retardation: developing pharmacoIn: Ratey JJ, ed. Mental retardation: developing pharmacotherapies.

72 Tyrer SP, Walsh A, Edwards DE, Berney TP, Stephens DA. Factors associated with a good response to lithium in aggressive mentally handicapped subjects. Progress in Neuropsychopharmacology 1984;8:751-5.

73 Aman MG, Kern RA. Review of fenfluramine in the treatment of developmental disabilities. 7 Am Acad Child Psychiatry 1989;28:549-65.

74 Chandler M, Barnhill LJ, Gualtieri CT. Amantadine: profile of use in the developmentally disabled. In: Ratey JJ, ed. Mental retardation deve DC: American Psychiatric Press, 1991:139-62. 